\title{
Inventory Control System for Vaccines Distribution With Model Predictive Control In Hospital
}

\author{
Lenny Margaretta Huizen ${ }^{1, *}$, Mustafid ${ }^{2}$ \\ ${ }^{1}$ Magister Program of Information System, School of Postgraduate Studies, Diponegoro University, Semarang - Indonesia \\ ${ }^{2}$ Department of Statistics Faculty of Sains and Mathematic, Diponegoro University, Semarang - Indonesia
}

\begin{abstract}
Inventory control of vaccine amounts is intended to allow the vaccine supply in the pharmacy to be balanced between the stored vaccine and the vaccine released so that the investment is minimized. The research aims to apply inventory control system to minimize inventory quantities while ensuring vaccine availability. Model Predictive Control is used to find minimal cost based cost function through vaccine supply level, vaccine order, and vaccine cost. The results obtained for 4 months by comparing the calculation of hospital methods with Model Predictive Control is the number of orders can be minimized in accordance with the average demand with the amount of existing stock so as to minimize the costs incurred for the purchase of vaccines. The Model Predictive Control can be used to calculate the number of orders to be ordered with an uncertain vaccine request.
\end{abstract}

Keywords: Model Predictive Control; Vaccine; Inventory Control Systems.

\section{Intoduction}

Vaccines are biological products made from germs that have been attenuated or switched off so they work to produce active immunity against certain diseases [1] and become one way that can be used to prevent and control disease outbreaks [2]. Vaccine storage is different from storing other drugs, which must be stored in a temperature of $2^{\circ} \mathrm{C}$ to $8^{\circ} \mathrm{C}$.

In the immunization program, the vaccine is a major component in which its availability must be guaranteed to the extent that the vaccine has a special standard that serves to select the vaccine when it is manufactured in a pharmaceutical or pharmaceutical factory, while in the distributor to the distribution chain within the hospital [3] vaccine inventory must be managed properly. Inventory management is part of supply chain management that includes a process of planning, organizing, and controlling sustainable inventory. The purpose of supply management is to minimize investment in inventory so as to balance supply and demand.

The scope of inventory management involves waiting times, message costs, maintenance of goods, estimated goods, valuation of goods, forecasting the price of future oods, storage, quality management, return defects, and demand forecasting [4].

Most of the costs in the world of health are represented by the pharmaceutical department [5]. The goal of pharmaceutical management is to keep the supply of drugs and vaccines constantly available at all times. Lack of vaccine stocks can lead to disruption of activity in hospital services and vaccine supplies, on the contrary, can lead to increased costs in the purchase and storage of vaccines.

In a supply chain system other than essential to managing inventory, it is also very important to forecast changes in needs in inventory [6-7]. Demand changes are a frequent problem with inventory systems [8], in addition to the uncertainty of the number of requests and delays in delivery are also a problem in the supply chain [9]. The challenge faced in managing inventories is a demand that exceeds the amount of supply that can lead to stock shortages [10]. Inventory management is essential for hospitals so that the patient's needs for vaccines can be met but can minimize economic resources. It is necessary to regulate the amount of inventory so as to ensure the fulfillment of patient demand for a minimal cost [11]. So controlling in the supply chain is needed to calculate the safety stock so as to recalculate the positions of goods based on demand data [12].

There have been many developed methods used to control inventory quantities by minimizing costs. Predictive Control Model (MPC) is one of the methods used to analyze stock control based on minimal cost. MPC is a control system using prediction results in issuing input controls. Based on the optimal input control is used for some time to [13]. MPC is used to find minimal costs based on drug supply levels, drug orders, and drug prices [10].

The purpose of this study is how to control inventory with uncertain demand by using minimal cost by looking at the average use of vaccines in the past year.

*Corresponding author: lenny_margaretta@yahoo.com 


\section{Literature review}

\subsection{Inventory System}

In hospital management inventory becomes one of the important things because it affects consumption and costs [4]. Vaccine inventory management aims to ensure availability. An inadequate vaccine supply system can lead to an excess supply and can lead to a void in the supply system.

An Excessive amount of vaccine stock has expired risk, and damage if not stored properly. This, of course, can affect the level of vaccine service at the hospital. Effective inventory management requires oversight and priority setting in every purchase and distribution of vaccines [4]. The amount of vaccine supply in the pharmaceutical department depends on demand and order, so the number of supplies in each vaccine will be different. The optimal amount of inventory can cause the cost to be optimized. Inventory costs consist of vaccine booking costs, vaccine pricing, and vaccine storage costs.

In the inventory control system to note is the time required for the order until the ordered goods came. The amount of inventory for each vaccine can be represented by a discrete linear model [8].

$$
s_{i}(t+1)=s_{i}(t)+o_{\mathrm{i}}\left(t-\tau_{i}\right)-d_{i}(\mathrm{t})
$$

For $s_{i}(t)$ represents the amount of drug supply $(i)$ at time $t$, plus the order quantity of the ordered $\left(o_{i}\right)$ order at time $t$ minus the pending order at time $\tau_{i}$, subtracted by the number of untreated drug requests at time $t$ [8], then subtracted by the number of drug requests $\left(d_{i}\right)$ not yet given at time $t$ [8]. In this study used only the number of orders at time $t$ without minus the pending order at time $\tau$ i. So that equation is

$$
s_{i}(t+1)=s_{i}(t)+o_{\mathrm{i}}(t)-d_{i}(\mathrm{t})
$$

\subsection{Model Predictive Control (MPC)}

Predictive Control Model is a method of controlling stock based on a process model that is used directly to design technology-based controller. The model is used to predict the output based on the past which is then subtracted by reference trajectory resulting in a new prediction value and the old prediction value is not used. The results are used to optimize the results by using cost function. The result is then used to calculate the upcoming output until the time of $N$ (Control Horizon) subsides.

The steps in calculating MPC are :

- Calculating inventory quantities by a process model (1) - To find the minimum value to the cost optimization with equation (4)

$$
\min _{o} j=\beta_{1} J_{1}(o, t)+\beta_{2} J_{2}(o, t)+\beta_{3} J_{3}(o, t)
$$

where $J_{1}$ is the stock level, $J_{2}$ the cost of ordering, while $J_{3}$ is an order. For $\beta_{1}, \beta_{2}$, and $\beta_{3}$ are fixed weights depending on each management objective.

To find the value of each of $J_{1}, J_{2}$ and $J_{3}$ are used equation (5-6).

- The value on $J_{l}$ :

$$
\min _{s_{i}, 0_{i} * i} \sum_{k=0}^{N} \sum_{i=1}^{N_{i}} c_{0, i} s_{i}(t+k)
$$

where for $\mathrm{C}_{o, i}$ is the cost of reserving the reserved vaccine for time $t$.

The value on $J_{2}$ :

$$
\min _{b i, 01} \sum_{\forall i}^{N} \sum_{k=0}^{N_{i}} P_{i=1} \delta_{i}(t+k) a_{i}(t+k)
$$

where $P_{i}$ is the price for the vaccine to be ordered.

- The value on $J_{3}$ :

$$
\min _{8 \mathrm{i}} \sum_{k=0}^{N} \sum_{\mathrm{i}=1}^{N_{i}} C_{0 p, i} \delta_{i}(t+k)
$$

where for Cop, $i$ is the cost of booking the vaccine to be ordered.

\section{Methodology}

In this study, the stages begin with the determination of input, process, and output. In this system, the inventory quantity is calculated by using the process model with equation (2), of which the result is subtracted by a set point that has been determined with average use for 4 months. From that result then optimized by looking for a minimum value of cost function at equation (4) by looking at boundary restriction which has been

\begin{tabular}{|c|c|c|}
\hline No & Constraint & Description \\
\hline 1 & $\operatorname{si}(\mathrm{t}) €_{S_{\min }^{\mathrm{i}}}^{\mathrm{i}} s_{\operatorname{man}}^{\mathrm{i}}$ & $\begin{array}{l}\text { The amount of inventory must be } \\
\text { between } s_{m=1}^{i} s_{m=x}^{i} \text { to avoid stock } \\
\text { out }\end{array}$ \\
\hline 2 & $\operatorname{oi}(\mathrm{t}) \in_{o_{\min }}^{\mathrm{i}} \mathrm{o}_{\operatorname{m}=\mathrm{s}}^{\mathrm{i}}$ & $\begin{array}{l}\text { Order quantity must be between } \\
a_{\min }^{i} o_{\max }^{\mathrm{i}} \text { to avoid overstock }\end{array}$ \\
\hline
\end{tabular}
determined with Table 1. From the result of processing of system that output reached is how much inventory to be purchased in accordance with minimal cost that will be used.

Table 1. Total inventory and order

The results were then compared with the system that runs on the hospital. So it will get how much the cost difference and vaccine orders.

\section{Result And Discussion}

This study uses historical data from 1 December 2017 29 March 2018, this study using 1 type of vaccine that is rotavirus, the price used is the selling price to the patient 
because it is impossible to use the actual price in this study. From the historical data in Table.2, it is found that the average use of 16 for each month so that safety stock can be obtained that is $10 \%$ of the average usage is 2 . The setpoint is set 4 with an estimate every week there are 4 vaccine requests.

The first step taken by the MPC model is to calculate the stock inventory every day $\left(s_{i}\right)$ with equation (2), so if the stock number is close to or equal to safety stock automatically ordering a set point. After the value is obtained then subtracted with the set point so that will get the new inventory amount. The number of new stocks will be used to calculate the minimum cost by using MPC with equation (4) by solving equation (5-7). The value of $J_{l}$ is the cost of saving, ie the cost incurred for vaccine storage. This fee is in the form of electricity payment every month. The calculation of electricity cost is adjusted with electric power at the hospital so that the cost of electricity is considered constant which is IDR $42,000 /$ month. The value of $J_{2}$ is used to calculate the price of the vaccine so that it is adjusted to the amount of vaccine to be ordered, this price is not the actual price but the selling price of the vaccine to the consumer, since it is impossible to give the actual price and the value of $\mathrm{J} 3$ is the cost of the message, the cost of the message includes monthly call charges, amounting to IDR 21,000. For more details can be seen in Figure 3

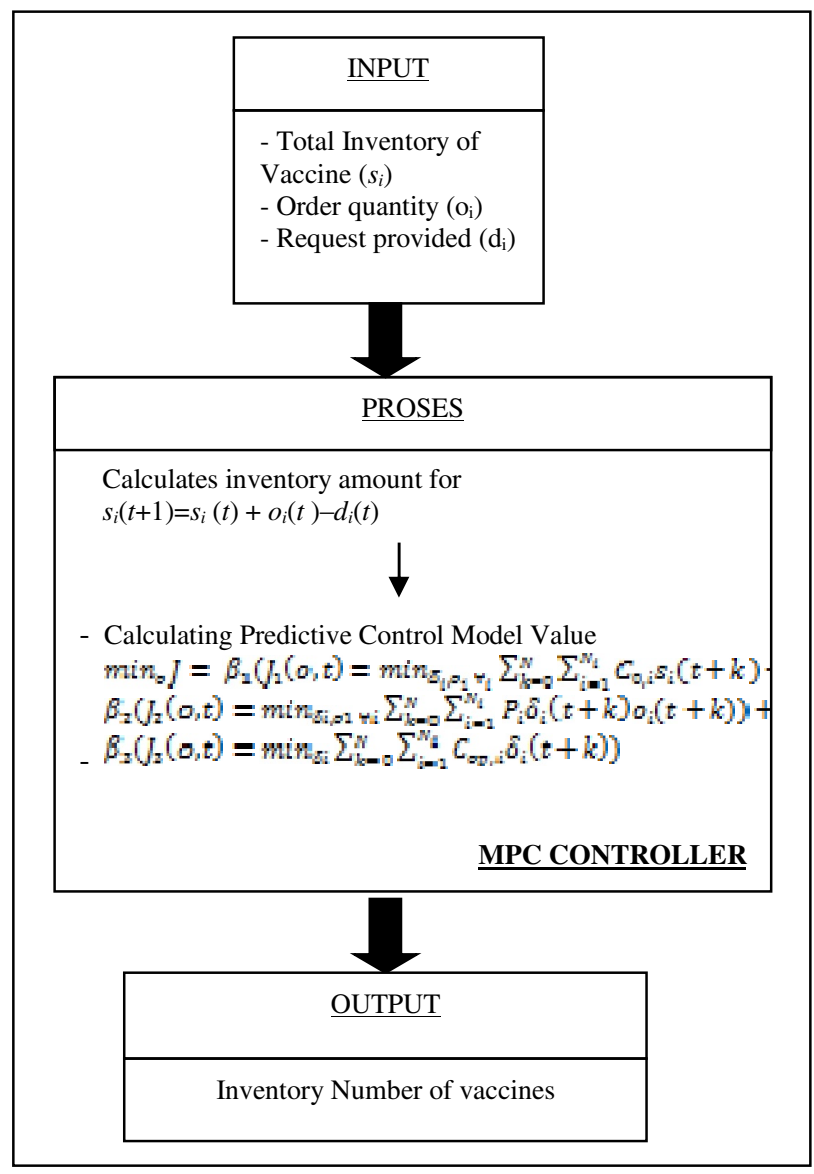

Fig. 3. Information System Framework on the Control System of Vaccine With MPC
The calculation in this study starts from 01 December 2017 done calculation of vaccine stock, calculations are done every day in order to know whether the amount of stock is still enough to meet the needs of the vaccine every day. Vaccine bookings are made when the stock is close to the amount of stock safety and the amount of order made based on the remaining stock less the set point. So the ordering of the vaccine is done again on 18 December 2017, and the goods come 19 December 2017. The calculations are continued by calculating the save cost, the price of the message and the cost of the message, then to the three costs each given a weight of 1 for $\beta_{1}, \beta_{2}$, and $\beta_{3}$ as each having the same goal.

In the table 3 can be seen that there is 7 times the order within 4 months of the hospital, whereas the use of MPC can be done with reservations as much as 6 times, this, of course, can save the cost budget that is in the hospital but still meet the needs hospital.

Table 3. Historical Data Vaccine Rotavirus 1 December 2017 29 March 2018

\begin{tabular}{|c|c|c|c|c|c|}
\hline \multirow{2}{*}{ Date } & \multicolumn{2}{|c|}{ Real } & \multicolumn{2}{|c|}{ MPC } & \multirow{2}{*}{$\begin{array}{c}\text { Demand } \\
(d i)\end{array}$} \\
\hline & $s_{i}$ & $\mathrm{O}_{\mathrm{i}}$ & $s_{i}$ & $\mathrm{O}_{\mathrm{i}}$ & \\
\hline 01-Dec & 11 & 0 & 11 & 0 & 1 \\
\hline 02-Dec & 10 & 0 & 10 & 0 & 0 \\
\hline 03-Dec & 10 & 0 & 10 & 0 & 3 \\
\hline 04- Dec & 7 & 10 & 7 & 0 & 0 \\
\hline 09-Dec & 17 & 0 & 7 & 0 & 1 \\
\hline 12-Dec & 16 & 0 & 6 & 0 & 1 \\
\hline 16-Dec & 15 & 0 & 5 & 0 & 1 \\
\hline 18-Dec & 14 & 0 & 4 & 0 & 4 \\
\hline 19-Dec & 10 & 0 & 0 & 4 & 0 \\
\hline 22-Dec & 10 & 10 & 4 & 0 & 0 \\
\hline 23-Dec & 20 & 0 & 4 & 0 & 1 \\
\hline 30- Dec & 19 & 0 & 3 & 1 & 4 \\
\hline 31-Dec & 15 & 0 & 0 & 4 & 0 \\
\hline 06- Jan & 15 & 0 & 4 & 0 & 2 \\
\hline 07- Jan & 13 & 0 & 2 & 0 & 0 \\
\hline 08- Jan & 13 & 0 & 2 & 2 & 0 \\
\hline 16- Jan & 13 & 0 & 4 & 0 & 3 \\
\hline 17- Jan & 10 & 0 & 1 & 3 & 0 \\
\hline 18- Jan & 10 & 0 & 4 & 0 & 0 \\
\hline 19- Jan & 10 & 0 & 4 & 0 & 0 \\
\hline 20- Jan & 10 & 0 & 4 & 0 & 2 \\
\hline 21- Jan & 8 & 0 & 2 & 2 & 0 \\
\hline 26- Jan & 8 & 10 & 4 & 0 & 2 \\
\hline 27-Jan & 16 & 0 & 2 & 0 & 1 \\
\hline 28-Jan & 15 & 0 & 1 & 3 & 0 \\
\hline 03- Feb & 15 & 0 & 4 & 0 & 4 \\
\hline 04- Feb & 11 & 0 & 0 & 4 & 3 \\
\hline $05-\mathrm{Feb}$ & 8 & 0 & 1 & 3 & 0 \\
\hline 10- Feb & 8 & 0 & 4 & 0 & 3 \\
\hline $11-\mathrm{Feb}$ & 5 & 0 & 1 & 3 & 0 \\
\hline 12- Feb & 5 & 0 & 4 & 0 & 0 \\
\hline 13- Feb & 5 & 0 & 4 & 0 & 0 \\
\hline 14- Feb & 5 & 0 & 4 & 0 & 1 \\
\hline 28-Mar & 16 & 0 & 1 & 3 & 0 \\
\hline 29-Mar & 16 & 10 & 4 & 0 & 0 \\
\hline$:$ & $:$ & $:$ & $:$ & $:$ & $\therefore$ \\
\hline 30-Mar & 26 & 0 & 4 & 0 & 0 \\
\hline
\end{tabular}




\section{Conclusion}

In the inventory control system vaccine amount, the use of MPC is required to control the number of orders to be ordered, the use of MPC can save 10 vaccines so as to save storage capacity, the cost for the purchase of vaccines, but the ordering costs to increase because there is an adjustment between ordering and existing inventory so that in 1 week can happen order 2 times or no order at all..

\section{References}

1. A.D. Pasquale, P. Bonani, N. Garcon, L.R. Stanberry, M.E. Hodhod, F.T.D. Silva, International Journal of Vaccine 34, 6672-6680 (2016)

2. V.A. Truong, International Journal of Vaccine 30, 6175-6179 (2012)

3. P. Yadav, P.P. Lydon, J. Oswald, M. Dicko, M. Zaffran, International Journal of Vaccine 32, 67256732 (2014)

4. V. Singh, H. Singh, S. Singh, International Journal on Mechanical Engineering and Robotics (IJMER) 3, 19-22 (2015)
5. P. Kelle, J. Woosley, H. Scneider, International Journal of Operations Research for Health Care 1, 54-63 (2012)

6. M. Mustafid, A.S. Karimariza, F. Jie. International Journal of Agile Systems and Management 11, 1-22 (2018)

7. D. Hai, Z. Hao, L.Y. Ping, Procedia Engineering 15, 1154-1159 (2011)

8. D. Fu, C.M. Ionescu, E.H. Aghezzaf, R.D. Keyser, IFAC Proceedings 46, 1608-1613 (2013)

9. I. Jurado, J.M. Maestre, P. Velarde, C.O. Martinez, I. Fernandez, B.I. Tejera, J.R.D Prado, International Journal of Computers in Biology and Medicine 72, 248-255 (2016)

10. C.W.Craighead, J. Blackhurst, M.J. Rungtusabatham, R.B. Handfield, International Journal of Decision Sciences 38, 131-156 (2007)

11. J.M. Maestre, M.I. Fernandez, I. Jurado, International Journal of Control Engineering Practice 71, 120-128 (2018)

12. A.D. Sabila, M. Mustafid, S. Suryono, E3S Web of Conferences 31, 11015 (2018)

13. E. Camacho, C. Alba, C. Bordons, Model Predictive control, Advanced textbooks in control and signal processing, Verlag London (2007) 